\title{
Variations and Relationship of the Flounder and the Plaice.*
}

By

F. B. Stead, B.A.

There can be no question of the importance of the subjects treated of in this paper; and the results are certainly such as to attract attention. This fact makes it all the more disappointing that the author's method is not calculated to inspire confidence in the accuracy of his conclusions. Before attempting to justify this statement, we may give a brief account of the paper as it stands.

After giving an extensive bibliography, the author passes on in his second chapter to a statement of the method of the investigation, and of the notation by which he finds it necessary to state his results. In the next chapter a table is given showing the extent of variation of particular characters in the species considered, and the degree in which the variations of these same characters in both forms may coincide. The influence of sex and age, and the character and development of the scales, is next treated of, and the following chapter is devoted to a statement of the differences which obtain between the different "local forms" in the North Sea and the Baltic. The rest of the paper is taken up with a consideration of the relations between the local forms and the species, an account of Pleuronectes pseudoflesus, certain morphological and biological observations, and a summary of results. We may now consider the more important parts of this paper in detail,

The method of investigation consisted in examining "a large number" of specimens of each species in respect of no less than thirty-six characters. Of these eleven were finally selected as sufficing to distinguish the species one from another, as well as the individual forms of each species from different localities.

* "Variation und Verwandschaft von. Pl. flesus L. und Pl. platessa L., untersucht mittelst der Heincke'schen Methode," von Georg Duncker. Wiss. Meeresuntersuch herausgegeben von d. Komm. zur Wiss. Untersuch d. deutschen Meere in Kiel. Heft. 2, 1896. 
These characters were the number of vertebræ in the caudal peduncle and in the tail, the number of vertebræ which have no median hæmapophysis, and the total number of vertebræ; the number of fin rays in the dorsal and anal fins; the length of the caudal peduncle, and its mean height; the total length of the body without the caudal fin; the length of the head on the ocular side; and the number of branchiostegal rays. In order to eliminate small errors of measurement, such as those which result from the shrinkage of specimens which have been preserved in spirit, and to give at the same time a clearer expression of the main facts of variation, the total range of variation in respect of each particular character was legitimately divided into a small number of arbitrarily selected divisions. Into one of these divisions a number of individuals, all varying slightly from one another, would then fall; and the individuals in question would be regarded as identical in respect of the particular character examined. The author has, however, considered it necessary to adopt a notation to represent the "variation degrees" of each character, which makes his paper by no means easy to read. The several characters of particular individuals are represented by formulæ which the reader has to interpret by reference to the chapter on the method employed, whenever they occur. Thus we are told that the "Extreme Flounder form" has characters represented by the formula $5+19+9=33$. $a$ a $\delta a(1)$.

Having explained his method, the author gives in his next chapter a table, in which the limits of variation for each particular character in the two species considered are indicated.

In two forms so closely allied as the plaice and the flounder, a considerable part of the entire range of variation for any character is often common to the two species.

The table given shows in an interesting manner the degree to which the variation ranges of the several characters are distinct in the two species. Thus the number of fin rays in the dorsal fin varies from $51-65$ in the flounder, and from $61-80$ in the plaice.

The total range of variation is 30 , and of these 30 possible variations there are 5 which are common to both species. This fact is expressed by saying that the percentage of variation common to the two species is 17 per cent. It is noteworthy that in respect of the depth of the body and the length of the head-the measurements in each case being expressed as percentages of the body length-there is no difference in the ranges of variation for the two species.

Our author next deals with the influence of age and sex. This part of the subject appears to us to be somewhat inadequately treated. In dealing with local forms, the author states that he examined exclusively "the grown up" specimens ("erwachsenen materials") without defining 
the term. An examination of the tables given for plaice reveals the fact that the majority of the specimens examined varied in length from 20-30 cms. (about 8-12 in.). To assume that all these individuals were "grown up," and that the influence of age need not therefore be considered, is to assume what appears to us to require proof. Our author himself points out that the influence of age might be such as to lead an observer to erroneous conclusions with regard to the influence of locality. But he neither investigates the relation of differences in age to any particular character, nor does he examine for each locality a sufficient number of individuals of about the same size to render it probable that the differences due to variation in age may be safely left out of consideration. It is clear that if a sufficiently large number of forms of the same size were examined, the characters for fishes from each locality might be considered in relation to the most probable age for that size. But even so, the influence of the locality on the rate of growth would have to be determined.

With regard to the influence of sex, our author states that in both species the females are always broader, and have longer heads than the males. In the males the number of vertebræ is somewhat smaller than in the females.

The subject of the development of scales in the two species is next considered. To this we would draw special attention, as it is in respect of the character of the scales that the two species differ most strikingly from one another, and the author's observations on the point are distinctly interesting. It is pointed out, that in both species cycloid scales begin to develop (when the fish is $1.5-2.0 \mathrm{cms}$. long) over the whole surface of the body, at the bases of the caudal fin rays, on the cheeks and on the præoperculum. The plaice develops these scales on the ocular side along the inside rays of the dorsal and anal fins, and at the bases of the pectoral and ventral fins. The scales lie embedded in the skin, separated for the most part from one another, and it is only in particular parts, for instance the caudal peduncle on the ocular side, that they overlap. In the female plaice, development of scales rarely proceeds beyond this stage; in the male, changes may occur after maturity has been reached, but these changes only consist in a transformation of the cycloid scales into the ctenoid condition. In the flounder, on the other hand, the cycloid scales become transformed in various parts of the body into a ctenoid, and even more complicated condition, while the fish is still only $2-3 \mathrm{cms}$. long.

The change of a cycloid into a ctenoid scale proceeds in the following manner:-The posterior edge of the scale becomes raised out of the enclosing epithelium, and a layer of hard transparent substance bearing spines is laid down over the surface of the scale. This layer, which is 
divided presumably from the epithelium, travels forwards over the surface to its anterior edge, and spreads over part of the under surface posteriorly. When this process is complete the scale is said to have reached the Dorn-Stadium.

In the next chapter the author deals with the different local forms of the plaice and flounder from different localities in the North Sea and the Baltic. We do not propose to give a detailed statement of his conclusions, because it appears to us that the evidence on which these are based is quite insufficient. Taking the first locality dealt with as an example, we may note that the author diagnoses 20 male and 8 female flounders. He then takes the most common measure (in 28 individuals) for each character considered, and writes a formula which he calls Die Mittelformel für die Königsberge Form. Further, a table is appended in which the frequencies of the several variations of each character in the individuals examined is expressed in percentages of the total number of individuals. Thus we are informed that 55 per cent. of the 20 male flounders from Königsberg have 36 vertebræ.

It appears to us that little reliance can be placed on conclusions which are drawn from an examination of so small a number of individuals: and it is simply misleading to express the results of such examination in percentages, when fewer even than a hundred individuals have been examined.

The author proceeds to summarise his results by giving two formulæ, expressing the characters of Baltic and North Sea flounders. We are not altogether sure what meaning the author attaches to these generalised formulæ. The formulæ, assuming the results obtained for the separate localities to be accurate, express the most common measurements of the several characters in all the individuals examined from the Baltic and the North Sea, and they may be said to show how in a general way the flounders from these two regions differ from one another in respect to each of the several characters considered. But it would, we think, be a mistake to take these formulæ as expressing the combined characters of the ideal form which the environmental forces were tending to produce in these seas. If it is desired to show the direction in which evolution is tending to transform these populations, account must be taken of the facts of correlation. In a paper on certain correlated variations in Carcinus moenas, ${ }^{*}$ it has been pointed out by Weldon that before we can estimate the changes at present going on in a race or species, we must know, among other things, $(a)$ the percentage of animals which exhibit a given amount of abnormality with regard to a particular character, and $(b)$ the degree of abnormality of other organs, which accompanies a given abnormality of one. The ideal form of which

* Weldon. Proc. Roy. Soc., vol 54., p. 318. 
we spoke above is not to be got at by striking an average for each of the separate characters examined in the individuals from the region in question, but rather by determining not merely the amount of any abnormality, but also the degree to which it is associated with other abnormalities. We think we are right in saying that the laws of correlation do limit, and to some extent determine, the directions which evolution may take. In dealing with local forms, these considerations ought not to be ignored.

We may make our point of view clearer by reference to the formulæ given by our author, which denote what he calls the "extreme flounder form," or the "extreme plaice form." These formulæ are arrived at by taking the extreme variations of the several characters in the flounder and the plaice, contrasting them in this way as much as possible. The formulæ thus obtained represent the sum of a number of separate possibilities; but it by no means follows that the several extreme characters, which are separately possible, are possible in combination with one another in a single individual, and, in point of fact, as an examination of the tables shows, there is not a single instance of either of these extreme forms among the individuals examined by the author.

Our author having, as the result of his investigation into the local forms, taken up the position that the relationship between the two species in the Baltic is closer than in the North Sea, finds support for this view in the existence of an intermediate form which inhabits the south-western part of the Baltic, and which was first described by Gottsche as a variety of the plaice, and named Pleuronectes pseudoflesus. This form differs from the flounder in having cycloid scales on its "blind side," and the ctenoid scales of the plaice on its ocular side. It differs, however, from the latter species, and approaches the former in having rows of scales on its lateral line, and on the bases of the dorsal and anal fin rays, which are more highly developed than the ctenoid scales, and represent, in fact, a stage in the development of the scales which is characteristic of the flounder. The question arises, whether it is an intermediate form or a hybrid. On the one hand, the fertility of the fishes would seem to point to the former hypothesis; on the other, the mingling of the specific characters (of the flounder and the plaice), and the rarity of its appearance, would seem to support the latter. Our author inclines to support the latter view, in opposition to Möbius and Heincke, "ohne dass ich einen wissenschaftlichen grund hierfür anzugeben vermöchte.”

A form has been described by Ekström and Smitt which is also intermediate between the flounder and the plaice, and differs very slightly from Pleuronectes pseudoflesus. This form, to which the name $\mathrm{Pl}$. glacialis has been given, is found on the western part of the 
north coast of North America, and on the north coasts of Asia and Europe.

Attention may now be drawn to the hypothesis concerning the origin of these closely allied forms, which the author tentatively puts forward. It is pointed out in the first place that the Baltic may be considered intermediate between the North Sea and the Arctic Ocean, as regards the populations it contains. Further, the Baltic plaice, which differ from those of the North Sea in the smaller number of their vertebræ and fin rays, and in the stronger and more conspicuous ctenoid scales which they possess (characters which may be said to be masculine), would, if these differences were intensified, come to resemble very closely the Arctic form $\mathrm{Pl}$. glacialis. On the other hand, the flounder in the eastern part of the Baltic tends to vary in the direction of a greater number of vertebræ and fin rays, and these characters are feminine. $P l$. glacialis may, then, be regarded as representing an extreme form of either the plaice with masculine characteristics, or the flounder whose characteristics tend to be feminine. Our author considers that of the forms under consideration, the plaice, judging from the rudimentary development of its scales, is the oldest; that this form was originally confined to northern latitudes; and that it wandered thence to the North Sea-without undergoing very much change; and to the northern coasts of Europe and Asia, where it gave rise to the variety glacialis. At the same time an immigration took place into the Baltic, through the Gulf of Bothnia, which was then open to the North, and the plaice approximated to the glacialis type. As a result of the influence of a mild climate, $P l$. glacialis became transformed to a flounder-like form. This latter spread over the North Sea and the Atlantic coasts of North America, and gave rise to a number of varieties.

In the meantime the original $P l$. glacialis of the Baltic disappeared, and this form only now remains in the more northern latitudes where it took its rise. It will be seen that this hypothesis attempts to account for the differences which obtain between the North Sea and Baltic plaice, and derives the flounder from a form like the plaice-the modern $P l$. glacialis being regarded as representing an intermediate stage in the evolution of the flounder.

In conclusion, we may note that the author carefully refrains from discussing the causes which have given rise to the local varieties he describes. He does not even enter into the question whether the local differences arise in the ontogeny of each individual, as the result of the direct action of the environment, or whether they are inherited: in other words, he does not, so far as we can make out, commit himself as to the real nature of the local varieties - whether they are to be regarded 
as distinct races or no. He says not a word of Natural Selection or of Lamarckian factors. We are very far from being disposed to complain of these omissions.

In his concluding paragraph the author justifies his research by showing that it points to this important fact, namely, that the morphology of an organism is not wholly dependent on internal formative forces-e.g., Heredity, and Variation due to interual causes-but is also directly influenced in a determinate manner by external, chemical, and physical forces. The author, unless we are much mistaken, is not here concerned with the causes of evolution: he is merely pointing to the fact that every individual is continually subject to external influences, which must have an effect on its structure, whether characters so acquired are inherited or not.

And these external influences may act directly to produce certain modifications in the individual during its lifetime, or indirectly in determining the incidence of selection, or in both of these ways. Leaving out, for the sake of argument, the possibility of inheritance of acquired characters, the external conditions must still be considered of the greatest import-a fact which will be appreciated when it is remembered that an individual cannot be rightly regarded as a naked bundle of characters transmitted from its parents, but as an organism endowed with certain inherited tendencies, and reacting during life to the conditions of its environment. There can be no question, then, of the value of research which is concerned with the examination of the effects of external conditions. And this makes us regret all the more that the author was not as careful in establishing his facts on a sure basis as he is cautious in expressing his opinion on the theoretical aspects of the subject. 